\title{
A Novel 53-kDa Nodulin of the Symbiosome Membrane of Soybean Nodules, Controlled by Bradyrhizobium japonicum
}

\author{
Till Winzer, ${ }^{1}$ Andrea Bairl, ${ }^{1}$ Monica Linder, ${ }^{2}$ Dietmar Linder, ${ }^{2}$ Dietrich Werner, ${ }^{1}$ and Peter Müller ${ }^{1}$ \\ ${ }^{1}$ Fachbereich Biologie, Molekulare Zellbiologie und Angewandte Botanik, Philipps-Universität Marburg, \\ Karl-von-Frisch-Straße, D-35032 Marburg, Germany; ${ }^{2}$ Fachbereich Humanmedizin, Institut \\ für Biochemie, Justus-Liebig-Universität Gießen, Friedrichstraße 24, D-35392 Gießen, Germany \\ Accepted 24 November 1998.
}

\begin{abstract}
A nodule-specific 53-kDa protein (GmNOD53b) of the symbiosome membrane from soybean was isolated and its LysC digestion products were microsequenced. cDNA clones of this novel nodulin, obtained from cDNA library screening with an RT-PCR (reverse-transcriptase polymerase chain reaction)-generated hybridization probe exhibited no homology to proteins identified so far. The expression of GmNOD53b coincides with the onset of nitrogen fixation. Therefore, it is a late nodulin. Among other changes, the GmNOD53b is significantly reduced in nodules infected with the Bradyrhizobium japonicum mutant 184 on the protein level as well as on the level of mRNA expression, compared with the wild-type infected nodules. The reduction of GmNOD53b $\mathrm{mRNA}$ is related to an inactivation of the sip $F$ gene in $B$. japonicum 184, coding for a functionally active signal peptidase.
\end{abstract}

Additional keyword: bacteroids.

In the symbiotic interaction between legume plants and gram-negative bacteria of the genera Rhizobium, Bradyrhizobium, Sinorhizobium, or Mesorhizobium a new plant organ, the root nodule, is formed. The nodule provides the physiological environment in which the bacteria are capable of fixing nitrogen. During nodule development and maintenance the coordinated expression of specific plant and bacterial genes is required. Nodule-specific, plant-encoded proteins are called nodulins (Legocki and Verma 1980). They are classified into early and late nodulins, depending on the time of expression of the corresponding genes before or with the onset of nitrogen fixation (Nap and Bisseling 1990). Generally, early nodulins are involved in the infection process and nodule morphogenesis, whereas late nodulins are involved in the interaction with the microsymbiont and in nodule metabolic activities (van Kammen 1984).

Corresponding author: Peter Müller, Fachbereich Biologie, Molekulare Zellbiologie und Angewandte Botanik, Philipps-Universität Marburg, Karl-von-Frisch-Straße, D-35032 Marburg, Germany.

Telephone: 00496421 282072; Fax: 00496421288997

E-mail: muellerp@mailer.uni-marburg.de

Nucleotide and/or amino acid sequence data are to be found at the NCBI data base as accession number AF065435.
During nodule development the rhizobia are released from the infection thread into the host cell in a process resembling endocytosis (Basset et al. 1977), forming a new compartment within the host cell, the symbiosome (Roth et al. 1988). This process requires membrane synthesis in great amounts (Verma 1992) via the ER (endoplasmic reticulum) and Golgi apparatus (Mellor and Werner 1987). The symbiosome is separated from the cytoplasm by the symbiosome membrane (SM). The SM plays a crucial role in the interaction of both partners, since all metabolite and signal exchanges are mediated through and controlled by it. Although derived from the plasma membrane (Verma et al. 1978) the SM shares features of both plasma and vacuolar membranes (Bassarab et al. 1986; Bassarab and Werner 1989; Mellor et al. 1985). In addition, several unique properties are found in the SM because of its specific role in symbiosis. Nodulins of the SM are the most likely candidates for mediating the specific functions of this membrane at the interface between both symbiotic partners. The exchange of metabolites across the SM has been recently reviewed by Udvardi and Day (1997). Of several nodulins located in the SM (Fortin et al. 1985; Mellor et al. 1989), nodulin 24 (Katinakis and Verma 1985; Cheon et al. 1994), nodulin 26 (Fortin et al. 1987; Miao et al. 1992), and GmENOD55 (de Blank et al. 1993) are the best characterized. Nothing is known about the function of nodulin 24, but nodulin 26 shows sequence homology to intrinsic membrane proteins (Sandal and Marcker 1988), which function as water and ion channels. As has been demonstrated by Chandy et al. (1996), nodulin 26 indeed performs an aquaporin activity. Little is known about the signals that are involved in the biogenesis of the SM. It has been shown that several signals of the rhizobial microsymbiont are required for a complete composition of the SM (Morrison and Verma 1987; Werner et al. 1988).

In this study, two Bradyrhizobium japonicum mutants were used, previously obtained by TnphoA mutagenesis and designated 132 and 184, respectively (Müller et al. 1995b). Mutant 184 exhibits an abnormal phenotype of central nodule tissue colonization. The number of infected cells is reduced and the number of bacteroids per infected cell is significantly lower than in wild-type infected cells (Müller et al. 1995b). The symbiotic phenotype of mutant 132 is characterized by rapid bacteroid degradation soon after bacteroid release from the 
infection thread, a process that results in the formation of large vacuoles within the infected cells of the central soybean nodule tissue. Immunohistological studies have shown that the SM nodulin composition of mutant 132 infected tissue differs from wild-type infected nodule tissue (Müller et al. 1995a). DNA sequencing revealed that in mutant 184 the transposon was inserted in a gene $(\operatorname{sip} F)$ homologous to prokaryotic type I signal peptidases (Müller et al. 1995a). The sipF gene has been shown to encode a functional signal peptidase (Bairl and Müller 1998). In B. japonicum, like in Escherichia coli and Rhodobacter capsulatus, the sipF gene is followed by the rnc gene, encoding RNaseIII (March et al. 1985; Rauhut et al. 1996). B. japonicum mutant 132 (Müller et al. 1995b) has been shown to carry a transposon TnphoA in sipS, the second functional type I signal peptidase (Müller et al. 1995a).

This paper reports on a novel 53-kDa soybean SM nodulin and its cDNA clone, which was isolated by reverse genetics. The amino acid sequence revealed no similarities to proteins identified so far. We show that this nodulin is expressed on a significantly lower level in B. japonicum mutant 184 infected nodules.

\section{RESULTS}

\section{Differences in the SM protein pattern between wild-type (B. japonicum 110spc4) and mutant (B. japonicum 184) inoculated nodules.}

SM proteins from soybean nodules 21 days after inoculation with B. japonicum 110 spc 4 or B. japonicum 184 were investigated by two-dimensional sodium dodecyl sulfate-polyacrylamide gel electrophoresis (SDS-PAGE). Analysis of the SM protein pattern revealed several striking quantitative differences between wild-type and mutant inoculated nodules (Fig. 1). In the SM of mutant inoculated nodules (Fig. 1B), some proteins were more abundant (Fig. 1B, arrow heads) while others were significantly reduced (Fig. 1B, circles). In particular, three polypeptides (Fig. 1A, a, b, c) with identical molecular masses of about $53 \mathrm{kDa}$, but different isoelectric

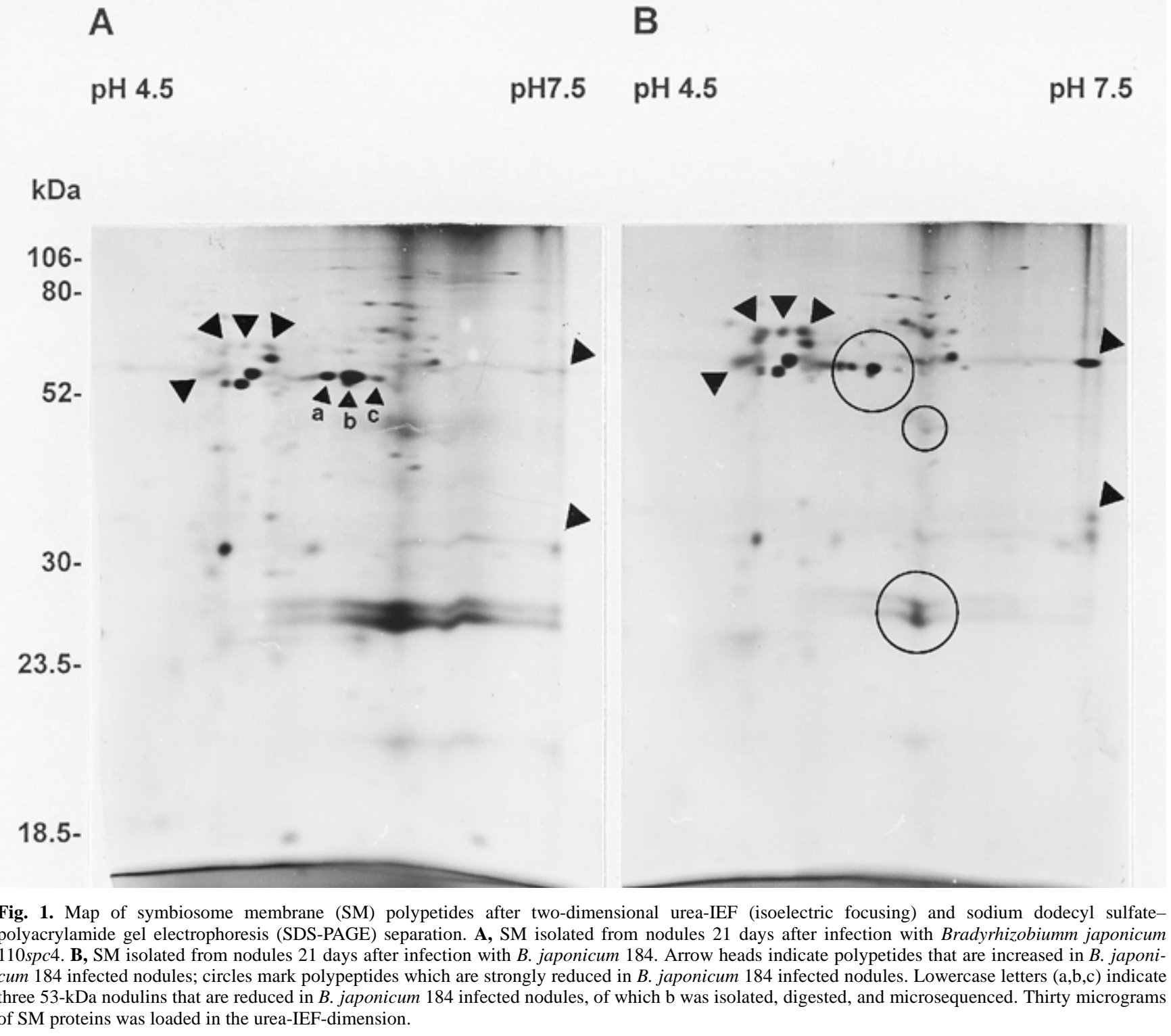


points, were reduced in the mutant inoculated nodules. These 53-kDa proteins are nodule specific since they were detected in a Western (immunoblot) analysis (Fig. 2), with a nodulespecific antiserum raised against SM proteins. The $53-\mathrm{kDa}$ proteins were thus named GmNOD53a, GmNOD53b, and GmNOD53c, respectively.

\section{cDNA cloning and sequencing of GmNOD53b.}

Further investigations were focused on the $53-\mathrm{kDa}$ nodulins. To obtain hybridization probes for cDNA library screening, GmNOD53a-c were isolated, purified, and subjected to $\mathrm{N}$-terminal amino acid sequencing. Unfortunately, all of the 53-kDa nodulins were N-terminally blocked. Because of the relatively small amounts of these nodulins in the SM and the fact that only limited amounts of SM could be obtained, the most abundant of the $53-\mathrm{kDa}$ nodulins, GmNOD53b (Fig. 1A, b), was chosen as the candidate for digestion by LysC and subsequent microsequencing of the generated peptides. GmNOD53b was purified by twodimensional SDS-PAGE. Approximately $50 \mu \mathrm{g}$ of GmNOD53b was subjected to proteolysis with the endoproteinase LysC; the peptides were separated by reverse-phase high-pressure liquid chromatography (HPLC) and sequenced. The amino acid sequences are given in the following list:

(K)TLLGALGGNYGNLRDYLMINSGMFQEIAK;

(K)VQEANWELYK; (K)VFENEREAVVAEANSELAK; (K)AVALREAELQREVERMNALTRTEK;

(K)VQLELNQFGLLIYNANVK;

(K)QLVDVPGHEYFSYLGQK

With degenerate primers deduced from peptides 1 and 3 and cDNA templates of soybean nodules, a DNA fragment of about 500 bp was amplified by PCR (polymerase chain reaction) that was subcloned in plasmid pGm53N. The DIG (digoxygenin-dUTP)-labeled cDNA insert of pGm53N was used to screen a soybean cDNA library (prepared from 21day-old nodules) constructed in $\lambda$ ZipLox. Screening of 100,000 recombinants yielded four hybridizing clones and their cDNA inserts were cloned in sequencing vector pBluescript $\mathrm{KS}^{+}$. Three clones (pGm53N1-3) contained 1,600-bp cDNA inserts and one (pGm53N4) a 1,400-bp cDNA insert. The nucleotide sequences of pGm53N1-3 were identical (Fig. 3). The sequence of pGmN4 represented the $3^{\prime}$ part of the 1,600-bp cDNA inserts of pGm53N1-3 and therefore turned out to be a truncated transcript of the identical gene. The inserts of pGm53N1-3 encoded an open reading frame of 1,431 bp. The deduced amino acid sequence of 476 amino acid residues is shown below the nucleotide sequence
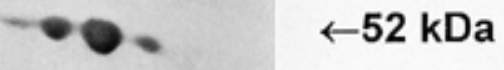

Fig. 2. Immunological detection of $53-\mathrm{kDa}$ nodulins in symbiosome membranes (SMs) isolated from nodules 21 days post infection with Bradyrhizobium japonicum 110spc4 after two-dimensional urea-IEF (isoelectric focusing) and sodium dodecyl sulfate-polyacrylamide gel electrophoresis (SDS-PAGE) separation. For the Western (immunoblot) analysis an SM nodulin-specific antiserum, kindly provided by D. P. S. Verma (Ohio State University) was used. First dimension was loaded with $80 \mu \mathrm{g}$ of SM proteins. in Figure 3. The peptide sequences determined from GmNOD53b are indicated as well. Because they turned out to be identical to the deduced amino acid sequences, this result confirms that indeed the inserts of pGm53N1-3 represent transcripts of the GmNOD53b gene. The predicted molecular mass of GmNOD53b is $52.4 \mathrm{kDa}$, which fits well with $53 \mathrm{kDa}$ as determined by SDS-PAGE. This indicated that pGm53N13 represent full-size clones of GmNOD53b. The screening procedure did not result in the isolation of cDNA clones coding for the nodulins GmNOD53a and GmNOD53c, respectively. The sequence of GmNOD53b was sent to the NCBI and EMBL sequence data bases so that related proteins could be searched for, but no significant homology was found to other proteins identified so far.

\section{Membrane association of GmNOD53b.}

The detection of GmNOD53a-c by a Western analysis, using an SM nodulin-specific antibody (Fig. 2), strongly indicated that these proteins are associated with the SM, which was confirmed by the observation that GmNOD53b is only partially soluble in non-ionic detergents such as Triton X-100 (A. Jacobi, unpublished results). However, the analysis of the deduced amino acid sequence by the PC/GENE computer program did not suggest a putative signal cleavage site and no transmembrane domains were identified, but several putative phosphorylation, myristoylation, and Asn-glycosylation sites were indicated within the sequence. The Lys-C digestion products were analyzed by MALDI-TOF (matrix-assisted laser desorption/ionization time-of-flight) mass spectrometry, but as the masses did not differ from the calculated masses of the amino acids of these peptides it was concluded that these parts of the protein were not modified by carbohydrate substitutions. However, positions 6-N and 44-N are indicated in Figure 3 by parentheses (N) to symbolize putative Asnglycosylation sites. The glycosylation of GmNOD53b was verified by a ConA-binding assay (data not shown). To examine whether GmNOD53b is a surface protein of the SM, the sensitivity of GmNOD53a-c to trypsin digestion was tested. If GmNOD53a-c were integral membrane proteins they were assumed to be protected from degradation, compared with cytoplasmic proteins. After $30 \mathrm{~min}$ of incubation with trypsin, GmNOD53a-c were significantly decreased and after 60 min they were no longer detectable on a Western blot (Fig. 4). The results of the ConA-binding assay and the protease protection assay indicate that GmNOD53b is associated with, but not integrated in, the SM.

\section{Expression of the GmNOD53b gene in soybean.}

The expression of the GmNOD53b gene during nodule development was examined by Northern (RNA) analysis. As shown in Figure 5A, a very slight accumulation of GmNOD53b mRNA was detected in 14-day-old nodules. After 18 days, the amount of GmNOD53b mRNA in nodules was significantly increased and detected at the same level in 22- and 26-day-old nodules. The first expression of GmNOD53b mRNA in 14-day-old nodules correlates with the onset of nitrogen fixation, as measured by the acetylene reduction assay. Thus, GmNOD53b belongs to the group of late nodulins (Nap and Bisseling 1990). To verify that the expression of GmNOD53b is restricted to nodules we probed RNA derived from uninfected roots and leaves with the insert of 
pGm53N (Fig. 5B). No hybridization signal was obtained in uninfected roots or leaves but it was in nodules, indicating the nodule-specific expression of GmNOD53b. The size of this transcript confirmed that the inserts of pGm53N1-3 represented full-size clones encoding the complete GmNOD53b.

\section{Differential expression of GmNOD53b in wild-type and bacterial mutant inoculated nodules.}

To examine whether the reduced concentration of GmNOD53b in the SM of B. japonicum 184 infected nodules (Fig. 1B) was due to a decrease of GmNOD53b mRNA accumulation, the level of GmNOD53b mRNA accumulation in both wild-type and mutant 184 infected nodules was studied. Furthermore, the expression of GmNOD53b in nodules infected with the B. japonicum mutant 132 was investigated. In this mutant a second signal peptidase gene of $B$. japonicum $(\operatorname{sip} S)$ is inactivated by a TnphoA insertion, resulting in a severely altered symbiotic phenotype (Müller et al. 1995a). As can be seen in Figure 6A, the level of GmNOD53b mRNA was significantly reduced in nodules infected with $B$. japonicum 184 (lanes 2 and 5), but not in nodules infected with $B$. japonicum 132 (lanes 3 and 6), compared with nodules infected with B. japonicum 110spc4 (lanes 1 and 4). Quantification of the hybridization signals in relation to the relative RNA amount of the probes with the SigmaGel computer program revealed that the expression of GmNOD53b was reduced to $60 \%$ of wild-type expression in B. japonicum 184 infected nodules while ubiquitin was expressed at the same level as in wild-type infected nodules (Fig. 6B). No influence of the mutation in sipS of B. japonicum 132 on the expression

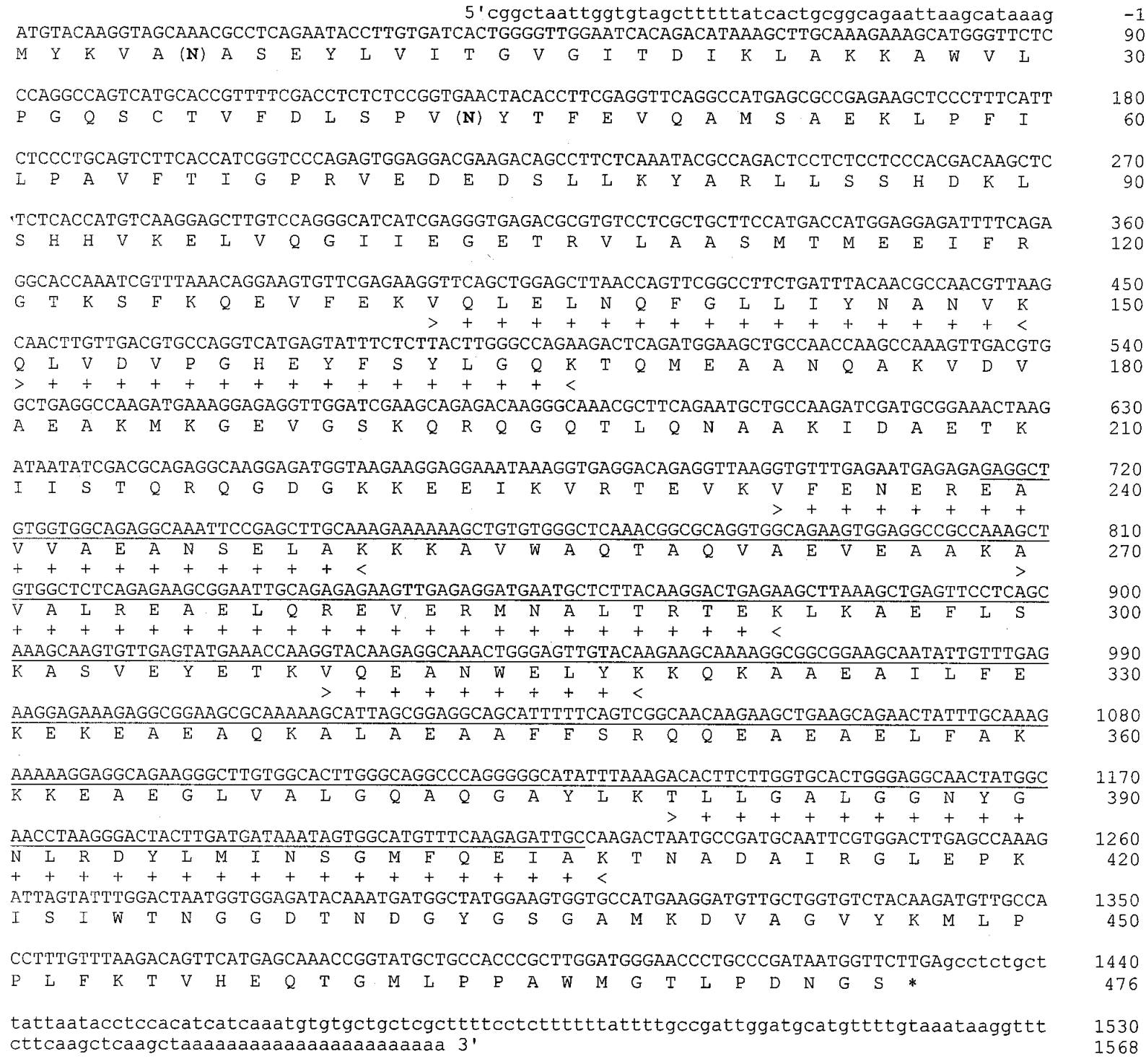

Fig. 3. Sequence of cDNA clones pGm53N1-3 coding for GmNOD53b. Underlined, sequence of PCR (polymerase chain reaction)-generated hybridization probe $(\mathrm{pGm} 53 \mathrm{~N})$. Amino acid sequence deduced from the cDNA is given below the nucleotide sequence in standard amino acid one-letter code. Regions of microsequenced peptides of GmNOD53b are indicated with $>++<$. Noncoding regions are shown in lowercase. Putative N-glycosylation sites are indicated by parentheses $(\mathrm{N})$. 
of GmNOD53b was detectable. Therefore, we suggest that the reduction of GmNOD53b in mutant 184 infected nodules is a consequence of a decrease of GmNOD53b mRNA caused by a TnphoA insertion into the sipF gene of B. japonicum 184.

\section{DISCUSSION}

Several nodulins that are located, or assumed to be located, in the SM, have already been described (Katinakis and Verma 1985; Fortin et al. 1985; de Blank et al. 1993; Fortin et al. 1987; Jacobs et al. 1987). cDNA clones encoding these proteins were obtained from nodule cDNA libraries by subtractive hybridization techniques. In this paper, we report a new nodulin (GmNOD53b) of the SM with a molecular mass of $53 \mathrm{kDa}$, cDNA clones of which were isolated by reverse genetics. At least two more $53-\mathrm{kDa}$ nodulins (GmNOD53a, GmNOD53c) are present in the SM, focusing very closely to GmNOD53b in the urea-IEF dimension. Because of their identical molecular mass and similar isoelectric point, we suggest that these $53-\mathrm{kDa}$ nodulins might be members of a new family of nodulins. In Southern hybridization experiments, two different EcoRI fragments were detected, with pGmNOD53b as a molecular probe (T. Winzer, unpublished results). However, isolation of cDNA clones for GmNOD53a and GmNOD53c by screening a nodule cDNA library with an RT (reverse transcriptase)-PCR-generated probe for GmNOD53b was not successful, but this may be due to the high stringency conditions of the screening procedure.

The determined nucleotide sequences of the GmNOD53b cDNA clones contain an open reading frame coding for 476 amino acids. All peptide sequences determined by microsequencing are found within the deduced amino acid sequence, giving evidence that indeed the isolated cDNA clones are coding for GmNOD53b. GmNOD53b exhibits no significant homology to proteins identified so far. Most likely, nodulins located in the SM are involved in signal transduction

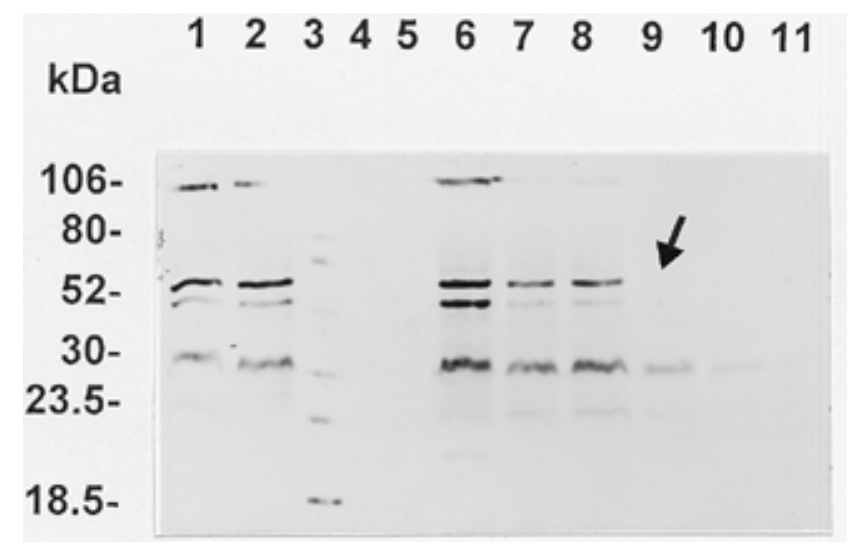

Fig. 4. Immunological detection of symbiosome membrane (SM) nodulins after digestion with trypsin. The $53-\mathrm{kDa}$ nodulins GmNOD53a-c were no longer detectable after digestion with trypsin for $60 \mathrm{~min}$ (arrow). Lane 1: incubation for $0 \mathrm{~min}$ without trypsin; lane 2: incubation for $120 \mathrm{~min}$ without trypsin, lane 3: prestained marker; lane 4: $0.5 \mu \mathrm{g}$ of trypsin; lane 5: $0.5 \mu \mathrm{g}$ of trypsin inhibitor; lane 6: incubation for 0 min with trypsin; lane 7 : incubation for 15 min with trypsin; lane 8: incubation for $30 \mathrm{~min}$ with trypsin; lane 9: incubation for $60 \mathrm{~min}$ with trypsin, lane 10: incubation for 90 min with trypsin; lane 11: incubation for $120 \mathrm{~min}$ with trypsin. and transport processes across the SM, since these functions are unique to the nodule.

Although the analysis of the amino acid sequence of GmNOD53b revealed no membrane or transmembrane domains, experimental evidence for the location of GmNOD53b in the SM is presented. Besides the detection of GmNOD53b by an SM nodulin-specific antibody, GmNOD53b is glycosylated and only partially soluble in non-ionic detergents such as Triton X-100. Therefore, we suggest that GmNOD53b is a surface protein of the SM, which is consistent with the sensitivity of GmNOD53b to trypsin digestion. The attachment of GmNOD53b to the SM is probably mediated by a lipidprotein linkage. This is indicated by eight putative myristoylation sites found within the sequence. A covalent proteinlipid linkage has also been considered as a membrane anchor for nodulin 24 (Cheon et al. 1994), since nodulin 24 does not have any membrane-spanning domain but a region homologous to the lipid-binding domain of bacterial lipoproteins. However, the predicted mass of GmNOD53b is in good agreement with the mass detected by SDS-PAGE. Alternatively, GmNOD53b could be linked to the SM by Nglycosylation of 6-N and/or 44-N. These carbohydrate modifications cause minor changes of the molecular mass of GmNOD53b that are therefore not expected to be detectable by PAGE.

Different trafficking pathways have been reported for membrane insertion of nodulins. Nodulin 24 has a cleavable signal sequence and is attached to the membrane, presumably by post-translational processing steps in the Golgi apparatus (Cheon et al. 1994). Nodulin 26 lacks a cleavable signal sequence and is cotranslationally inserted into the membrane (Miao et al. 1992). It has been shown that the first two trans-

\section{A}

\section{$\begin{array}{llllllll}\text { R4 } & \text { R7 } & \text { N10 } & \text { N14 } & \text { N18 } & \text { N22 } & \text { N26 }\end{array}$}

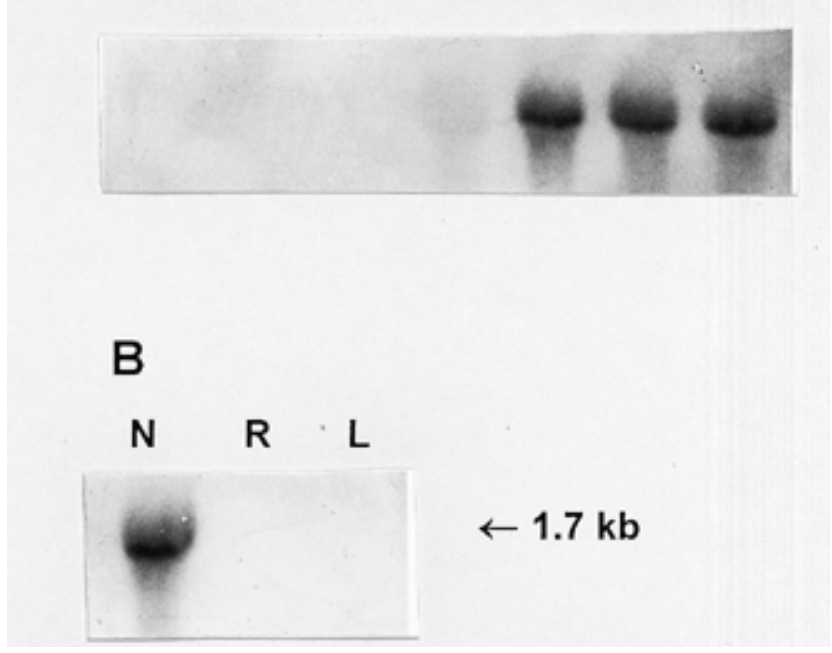

Fig. 5. Northern (RNA) analysis of GmNOD53b mRNA expression. A, Expression during nodule development. B, Expression in different plant tissues. Approximately $15 \mu \mathrm{g}$ of RNA from infected root segments (R4, R7) and nodules (N10, N14, N18, N22, and N26; numerals indicate days post inoculation), or nodules (21 days post inoculation), uninfected roots (R) and leaves (21 days post germination) was loaded per lane. The blotted RNA was hybridized with DIG-labeled cDNA-insert of pGm53N. 
membrane domains of nodulin 26 are sufficient for microsomal membrane insertion (Miao et al. 1992). We do not know the exact mechanism by which GmNOD53b gets attached to the membrane, since GmNOD53b exhibits neither a putative signal sequence nor transmembrane domains.

Expression studies of GmNOD53 revealed that indeed this protein is nodule specific. The first occurrence of GmNOD53b mRNA in nodules 14 days post infection coincides with the onset of nitrogen fixation. Therefore, GmNOD53b is a late nodulin. Furthermore, we have shown in this report that the amount of GmNOD53b in the SM of $B$. japonicum mutant 184 infected nodules is reduced. The reduction of GmNOD53b on the protein level is approximately equivalent to the reduction of GmNOD53b mRNA observed on the transcriptional level. The changes in the differential plant gene expression in soybean nodules are caused by a mutation in the genome of the microsymbiont. Although it was shown that a nonpolar sipF mutation results in a phenotype similar to mutant 184 (Bairl and Müller 1998), we cannot exclude polar effects of the TnphoA insertion on genes down-

A
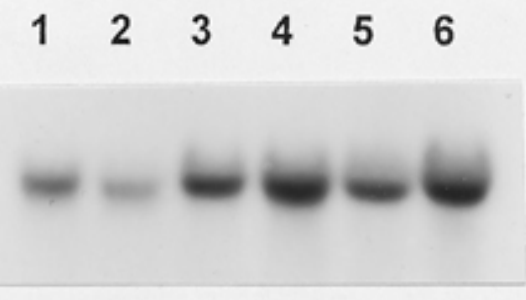

GmNOD53b

ubiquitin

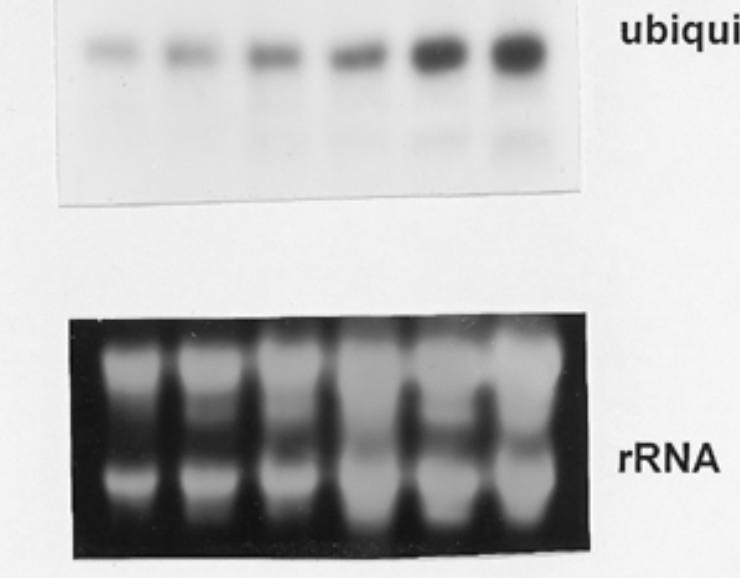

rRNA stream of $\operatorname{sip} F$. Therefore, in addition to the inactivation of the sipF gene, polar effects on downstream-located genes, such as $r n c$ and era, might be responsible for the mutant phenotype and hence for the altered protein composition of the SM. The influence of the microsymbiont on the SM nodulin composition has been reported previously (Morrison and Verma 1987; Mellor et al. 1989). Although in general the SM biogenesis is genetically controlled by the host plant (Verma et al. 1978; Mellor and Werner 1987), the release of the microsymbiont from the infection thread (Verma et al. 1988) and different signals of the microsymbiont are required for a complete induction of late nodulins and SM nodulins, respectively (Mellor et al. 1989; Morrison and Verma 1987). Little is known about the nature of these rhizobial signals in the later stages of symbiosis and the pathway of signal transduction. It is possible that the SipF signal peptidase in B. japonicum is involved in the processing of such rhizobial signal proteins, which may enhance the transcription of GmNOD53b mRNA.

On the other hand, RNaseIII encoded by the $r n c$ gene is involved in rRNA processing as well in processing of dou-

$\mathrm{B}$
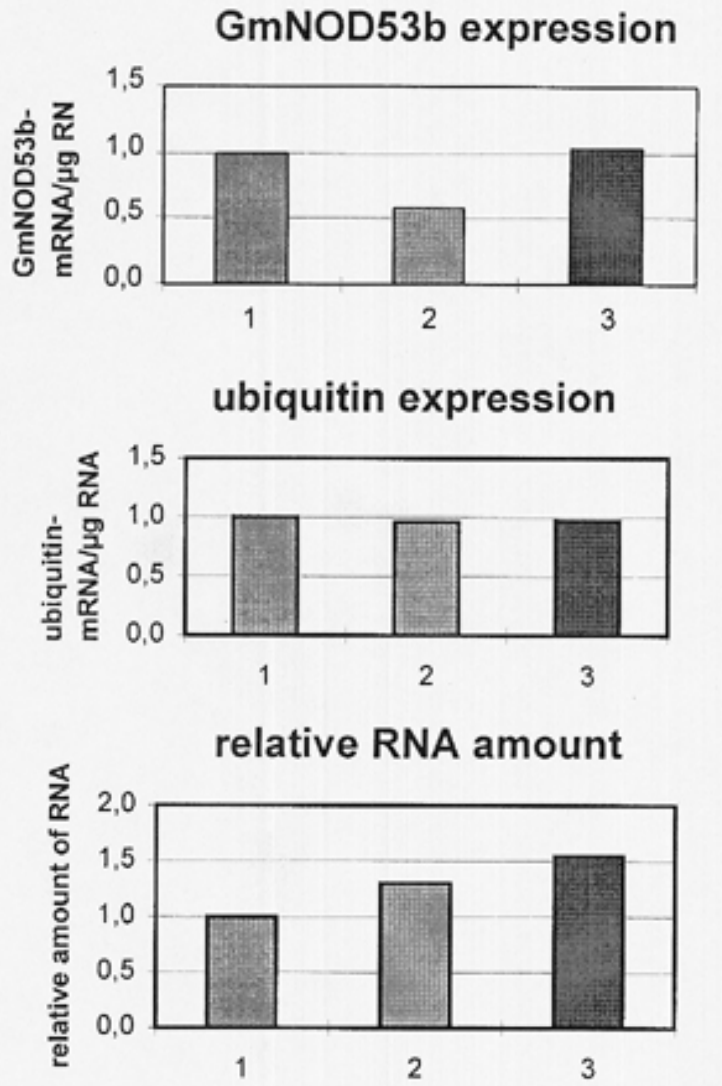

Fig. 6. Expression of GmNOD53b mRNA in wild-type and mutant inoculated nodules. A, Lanes 1 and 4 contain total RNA from wild-type infected nodules 21 days post inoculation ( 5 and $10 \mu \mathrm{g}$, respectively). Lanes 2 and 5 contain total RNA from mutant 184 inoculated nodules 21 days post inoculation ( 5 and $10 \mu \mathrm{g}$, respectively). Lanes 3 and 6 contain total RNA from mutant 132 infected nodules 21 days post inoculation ( 5 and $10 \mu \mathrm{g}$, respectively). Blotted RNA was hybridized with ${ }^{32} \mathrm{P}$-labeled cDNA insert of pGm53N, to determine expression of GmNOD53b. Integrity and equal RNA loading were confirmed by reprobing the membrane with a ubiquitin cDNA probe. B, Quantitative analysis of $\mathbf{A}$ with the SigmaGel computer program. Columns 1-3: relative expression of GmNOD53b, ubiquitin in (col. 1) Bradyrhizobium japonicum 110, (col. 2) B. japonicum 184, or (col. 3) B. japonicum 132 infected nodules, and relative amount of the RNA probe of these nodules. 
ble-stranded mRNA precursors. Since there are only single copies of the $r n c$ gene (Bairl and Müller 1998) and the rDNA (Kündig et al. 1995) in the genome of B. japonicum, a possible inactivation of the $r n c$ gene could be a rate-limiting step of bacterial growth and translation of rhizobial mRNAs in general. This would also explain the reduced growth rate of B. japonicum 184, compared with the wild type (Müller et al. 1995b). The infection process and nodule organogenesis require the controlled, time-dependent expression of both plant and bacterial genes. Thus, the inactivation of the rnc gene could disturb this coordinated gene expression, leading to the altered composition of SM proteins and the reduced expression of GmNOD53b we observed. A nonpolar sipF mutation (Bairl and Müller 1998) caused a symbiotic phenotype similar to that of mutant 184 , which favors a specific role of the SipF signal peptidase. Whether this nonpolar sipF mutant leads to a reduced GmNOD53b expression remains to be determined. In any case, the modulated expression of an SM nodulin by a defined mutation in the bacterial genome opens a new experimental approach to study the subtle plant-bacteria interaction in nodule development and SM formation. One of our future goals is the expression of GmNOD53b in E. coli in order to raise an antiserum against this particular protein. This will enable us to analyze the exact localization of GmNOD53b in the SM of soybean nodule thin sections.

\section{MATERIAL AND METHODS}

Plant material and growth conditions.

Glycine max L. Merr. 'Maple Arrow' (Plant Research Center, C.E.F.; Ontario, Canada) was infected with Bradyrhizobium japonicum 110spc4, 184, or 132 and grown under controlled conditions in a growth chamber as previously described (Werner et al. 1975).

\section{Isolation of the SM and protein determination.}

Nodules were harvested 20 to 25 days after infection and collected on ice. The SM was isolated as described (Mellor and Werner 1986) with some modifications (Bassarab and Werner 1987). The method of Lowry et al. (1951) was used to determine protein concentrations.

\section{Two-dimensional SDS-PAGE.}

Proteins of the SM were separated by two-dimensional SDS-PAGE (O'Farrell 1975). In the IEF (isoelectric focusing) dimension, the $\mathrm{pH}$ gradient was formed with a mixture of $1.6 \%$ (vol/vol) $\mathrm{pH} 5$ to 7 and $0.4 \%$ (vol/vol) $\mathrm{pH} 3.5$ to $10 \mathrm{am}-$ pholines (Serva, Heidelberg, Germany). The sample loading buffer contained $9.11 \mathrm{M}$ urea, $1.92 \%$ (vol/vol) NP-40, $1.54 \%$ ( $\mathrm{vol} / \mathrm{vol}$ ) $\mathrm{pH} 5$ to 7 and $0.38 \%$ (vol/vol) $\mathrm{pH} 3.5$ to $10 \mathrm{am}-$ pholines, and $4.8 \%$ (vol/vol) 2-mercaptoethanol. The SDSPAGE dimension was carried out as described by Laemmli (1970). Polyacrylamide gels were stained with silver nitrate or $0.25 \%$ (wt/vol) Coomassie brilliant blue R-250 in $40 \%$ (vol/vol) methanol and 10\% (vol/vol) glacial acetic acid.

\section{Western blotting and immuno staining.}

Proteins resolved by SDS-PAGE were electroblotted onto Immobilon membranes (Millipore, Eschborn, Germany) with a semi-dry-blot cell. The membranes were blocked with $3 \%$ (wt/vol) casein in standard PBS (phosphate-buffered saline) buffer, $\mathrm{pH} 7.5$, incubated $2 \mathrm{~h}$ with a polyclonal antiserum directed against nodulins of the SM (Fortin et al. 1985), followed by three 15-min washes with PBS buffer containing $0.3 \%$ (vol/vol) Tween 20. Immunoreactive proteins were visualized with alkaline phosphatase-linked goat anti-rabbit immunoglobin G.

\section{Detection of glycosylated SM proteins.}

Eighty micrograms of SM proteins was separated by SDSPAGE and blotted on a PVDF (polyvinylidene difluoride) membrane (Millipore, Eschborn, Germany). The membrane was blocked for $2 \mathrm{~h}$ in TBS (TBS: $50 \mathrm{mM}$ Tris- $\mathrm{HCl}, \mathrm{pH} 7.5$; $0.5 \mathrm{M} \mathrm{NaCl} ; 0.1 \mathrm{mM} \mathrm{MgCl}$; $0.1 \mathrm{mM} \mathrm{MnCl}_{2} ; 0.1 \mathrm{mM} \mathrm{CaCl}_{2}$; $40 \mathrm{mM}$ sodium citrate) containing $2 \%$ (wt/vol) BSA (bovine serum albumin) oxidized with metaperiodate. After being washed for $15 \mathrm{~min}$ in TBS, the membrane was incubated in TBS with $20 \mu \mathrm{g} \times \mathrm{ml}^{-1}$ peroxidase-labeled Concanavalin A (Sigma, Heidelberg, Germany). After the membrane was washed twice for $15 \mathrm{~min}$ in TBS, glycoproteins were detected with ECL reagents (Amersham Pharmacia Biotech Europe, Freiburg, Germany) according to the manufacturer's instructions. As a control, a second membrane was incubated in TBS containing $20 \mu \mathrm{g} \times \mathrm{ml}^{-1}$ peroxidase-labeled Concanavalin A and in addition $10 \mathrm{mM} \alpha$-D-glucose and $10 \mathrm{mM} \alpha$-D-mannose. No signal was detected in this control experiment.

\section{Protease assay.}

Fifteen micrograms of SM proteins was incubated with 0.1 $\mu \mathrm{g}$ of trypsin in $10 \mathrm{mM}$ Tris- $\mathrm{HCl}, \mathrm{pH} 8.0$ at $37^{\circ} \mathrm{C}$. The digestion was stopped by adding $0.1 \mu \mathrm{g}$ of trypsin inhibitor and heating the samples for $10 \mathrm{~min}$ at $100^{\circ} \mathrm{C}$ with sample buffer. The samples were resolved by SDS-PAGE and further analyzed by Western blotting.

\section{Protein purification, digestion, and protein sequencing.}

GmNOD53b of the SM was purified by two-dimensional SDS-PAGE. Coomassie-stained polyacrylamide gels were washed several times in distilled water to remove residual acetic acid completely. The spots corresponding to the GmNOD53b were excised with a scalpel from the gels and stored at $-80^{\circ} \mathrm{C}$ until digestion. The method of Eckerskorn and Lottspeich (1989) was used to digest $50 \mu \mathrm{g}$ of purified protein with the endoproteinase LysC. The generated peptides were separated on a $\mathrm{C}_{4}$ column (Vydac) at a flow rate of $200 \mu \mathrm{l} / \mathrm{min}$ in a $1 \% / \mathrm{min}$ gradient of $0.1 \%(\mathrm{vol} / \mathrm{vol})$ trifluoracetic acid (TFA) in water to $0.1 \%$ TFA in $80 \%$ ( $\mathrm{vol} / \mathrm{vol}$ ) acetonitrile. Peptides were sequenced by aminoterminal degradation (Edman and Begg 1967) in an automatic 477A protein/peptide sequencer (Applied Biosystems, Weiterstadt, Germany), following the protocol given by the manufacturer.

\section{RT-PCR and isolation of a 53-kDa nodulin hybridization probe.}

Total RNA from nodules, leaves, and uninoculated roots of G. $\max$ was isolated with Trizol reagent (GIBCO BRL, Eggenstein, Germany) according to the manufacturer's instructions. Poly $(\mathrm{A})^{+}$RNA was purified from initially prepared total RNA by oligo (dT)-cellulose affinity column chromatography with Poly (A) Quick mRNA Push Columns (Stratagene, Heidelberg, Germany), following the procedure described by the 
manufacturer. Total RNA and $\operatorname{Poly}(\mathrm{A})^{+}$RNA were stored at $-80^{\circ} \mathrm{C}$ until use.

Five micrograms of total RNA was used to synthesize single-stranded cDNA with Superscript II (GIBCO BRL, Eggenstein, Germany) according to the manufacturer's instructions. Single-stranded cDNA was used as template in a PCR with the degenerated primers 5'-GAIGCIGTIGTIGCIGAIGC-3' and 5'-GCIATITCITGIAACATICC-3' (I = Inosin) synthesized against the peptide motifs EAVVAEA and GMFQEIA determined from protein sequencing (see list in the Results). The 50- $\mu$ l PCR contained $10 \mathrm{mM}$ Tris/ $\mathrm{HCl} \mathrm{pH} 8.3,50 \mathrm{mM}$ $\mathrm{KCl}, 1.5 \mathrm{mM} \mathrm{MgCl}, 50 \mu \mathrm{M}$ concentrations of each dNTP, 0.7 $\mu \mathrm{M}$ concentrations of each primer, $0.05 \mathrm{U}$ of Taq DNA polymerase (Amplitaq, Perkin-Elmer Applied Biosystems, Weiterstadt, Germany) per $\mu \mathrm{l}$, and approximately $40 \mathrm{ng}$ of singlestranded cDNA. Amplification was performed as follows: five cycles of $45 \mathrm{~s}$ at $94^{\circ} \mathrm{C}, 30 \mathrm{~s}$ at 45 to $40^{\circ} \mathrm{C}$ and $45 \mathrm{~s}$ at $72^{\circ} \mathrm{C}$ (the annealing temperature was lowered by $1^{\circ} \mathrm{C}$ in each cycle) followed by 30 cycles of $45 \mathrm{~s}$ at $94^{\circ} \mathrm{C}, 30 \mathrm{~s}$ at $40^{\circ} \mathrm{C}$, and $45 \mathrm{~s}$ at $72^{\circ} \mathrm{C}$. The PCR was carried out in a Perkin Elmer GeneAmp PCR system 2400 thermo-cycler. The resulting 506-bp amplification product was purified and used as template for reamplification under the same conditions, with the exception that the primers carried at the $5^{\prime}$ end either an EcoRI or SalI restriction site, respectively. The re-amplified PCR product was purified with NucleoSpin extract-columns (Macherey-Nagel, Düren, Germany) ligated into EcoRI/SalIcut pBluescriptKS ${ }^{+}$and transformed into $E$. coli $\mathrm{DH} 5 \alpha$ to yield the plasmid pGm53N. The 506-bp insert of pGm53N was labeled by PCR described above either with DIG (digoxygenin-dUTP, Boehringer, Mannheim, Germany) or [ $\alpha$ $\left.{ }^{32} \mathrm{P}\right] \mathrm{dCTP}$ and used as a probe for cDNA library screening and Northern analysis, respectively.

\section{Nodule cDNA library construction and screening.}

A nodule-specific cDNA library was constructed from poly $(\mathrm{A})^{+}$RNA of 21-day-old nodules from $G$. max cv. Maple Arrow infected with B. japonicum 110spc4, using the Superscript Lambda system for cDNA Synthesis and $\lambda$ Cloning (GIBCO BRL, Eggenstein, Germany) as described in the manufacturer's instructions.

Fifty thousand recombinant $\lambda$ clones per $150-\mathrm{mm}$ dish were plated on $E$. coli Y1090 and screened by plaque hybridization. Replica plaque lifts were prepared on Hybond membranes (Amersham Pharmacia Biotech Europe, Freiburg, Germany) by standard procedures (Sambrook et al. 1989). After prehybridization for $1 \mathrm{~h}$ at $68^{\circ} \mathrm{C}$ in $5 \times \mathrm{SSC}(1 \times \mathrm{SSC}$ is $0.15 \mathrm{M} \mathrm{NaCl}$ plus $0.015 \mathrm{M}$ sodium citrate) $/ 0.1 \%$ (wt/vol) $N$-lauroylsarcosine Na-salt/0.02\% (wt/vol) SDS/1\% blocking reagent (Boehringer, Mannheim, Germany) the hybridization was performed in the same solution with $15 \mathrm{ng}$ of DIG-labeled insert of $\mathrm{pGm} 53 \mathrm{~N}$ per $\mathrm{ml}$ as probe for another $20 \mathrm{~h}$. The filters were washed $2 \times 5 \mathrm{~min}$ in $2 \times \mathrm{SSC} / 0.1 \% \mathrm{SDS}$ at room temperature and $2 \times 15 \mathrm{~min}$ in $0.1 \times \mathrm{SSC} / 0.1 \% \mathrm{SDS}$ at $68^{\circ} \mathrm{C}$. Subsequently, the filters were developed with the procedure described by Boehringer Mannheim for DIG-labeled probes. Positively hybridizing $\lambda$ clones were differentially screened a second and a third time under the same conditions. NotI/SalI inserts of those clones exhibiting hybridization to the probe were subcloned into pBluescriptKS ${ }^{+}$plasmids to yield plasmids pGm53N1-4.

\section{Northern hybridization.}

Total RNA samples (10 to $20 \mu \mathrm{g}$ ) were separated in morpholinepropanesulfonic acid (MOPS)/formaldehyde/1\% agarose gels and blotted on Hybond membranes (Sambrook et al. 1989). The blots were prehybridized for at least $1 \mathrm{~h}$ at $63^{\circ} \mathrm{C}$ in $0.5 \mathrm{M}$ sodium phosphate, $\mathrm{pH} 7 / 1 \mathrm{mM}$ EDTA/7\% (wt/vol) SDS/1\% (wt/vol) BSA. Hybridization with DIG-labeled or radioactively labeled $\left[\alpha-{ }^{32} \mathrm{P}\right] \mathrm{dCTP}$ insert of pGm53N as a probe was carried out in the same solution for another $20 \mathrm{~h}$. The filters were washed $2 \times 5 \mathrm{~min}$ in $2 \times \mathrm{SSC} / 0.1 \% \mathrm{SDS}$ at room temperature and $2 \times 15 \mathrm{~min}$ in $0.5 \times \mathrm{SSC} / 0.1 \% \mathrm{SDS}$ at $63^{\circ} \mathrm{C}$. Filters hybridized with a radioactively labeled probe were directly exposed to X-ray film (Kodak X-Omat AR) at $-80^{\circ} \mathrm{C}$ for 1 to 3 days. In the case of filters that were hybridized with a DIG-labeled probe, CDP-star (Boehringer, Mannheim, Germany) was used as a substrate for alkaline phosphatase, following the procedure described by the manufacturer. These filters were exposed to X-ray films for 2 to 5 min. Integrity and equal loading conditions were confirmed by reprobing a membrane with an $\left[\alpha-{ }^{32} \mathrm{P}\right] \mathrm{dCTP}$ labeled ubiquitin cDNA probe (Kouchi and Hata 1993).

\section{DNA sequencing and sequence analysis.}

DNA sequencing was performed according to the dideoxy chain termination method (Sanger et al. 1977), with the Thermo Sequenase fluorescent labeled primer cycle sequencing kit (Amersham Pharmacia Biotech Europe, Freiburg, Germany) and infrared-labeled universal M13 forward and reverse primers. The LI-COR DNA Sequencer 4000 (MWGBiotech, Ebersberg, Germany) was used for sequencing. Sequence analysis was performed by GENMON version 4.3 (GBF, Braunschweig, Germany) and PC/GENE (Oxford Molecular Biology, Oxford, UK).

\section{ACKNOWLEDGMENTS}

The SM nodulin-specific antiserum was kindly provided by D. S. P. Verma, Ohio State University, U.S.A. We would like to thank H. Steele for critically reading the manuscript. The financial support from the Deutsche Forschungsgemeinschaft (SFB 395, projects A4 and A6) is gratefully acknowledged.

\section{LITERATURE CITED}

Bairl, A.. and Müller, P. 1998. A second gene for type I signal peptidase in Bradyrhizobium japonicum, sipF, is located near genes involved in RNA processing and cell division. Mol. Gen. Genet. 260:346-356.

Bassarab, S., Mellor, R. B., and Werner, D. 1986. Evidence for two types of $\mathrm{Mg}^{2+}$-ATPase in the peribacteroid membrane from Glycine max root nodules. Endocytobio. Cell Res. 3:189-196.

Bassarab, S., and Werner, D. 1987. $\mathrm{Ca}^{2+}$-dependent protein kinase activity in the peribacteroid membrane from soybean root nodules. J. Plant Physiol. 130:233-241.

Bassarab, S., and Werner, D. 1989. $\mathrm{Mg}^{2+}$ pyrophosphatase, a tonoplast enzyme, in the peribacteroid membrane of Glycine max root nodules. Symbiosis 7:81-94.

Basset, B., Goodman, R. N., and Novacky, A. 1977. Ultrastructure of soybean nodules: Release of rhizobia from the infection thread. Can. J. Microbiol. 23:573-582.

Chandy, G., Roberts, D. M., and Hall, J. E. 1996. Water channel activity of wildtype and mutant nodulin 26 expressed in Xenopus laevis oocytes. Biophys. J. 70:A196.

Cheon, C.-I., Hong, Z., and Verma, D. P. S. 1994. Nodulin 24 follows a novel pathway for integration into the peribacteroid membrane in soybean root nodules. J. Biol. Chem. 269:6598-6602. 
de Blank, C., Mylona, P., Yang, W. C., Katinakis, P., Bisseling, T., and Franssen, H. 1993. Characterization of the soybean early nodulin cDNA clone GmENOD55. Plant Mol. Biol. 22:1167-1171.

Eckerskorn, C., and Lottspeich, F. 1989. Internal amino acid sequence analysis of proteins separated by gel electrophoresis after tryptic digestion in polyacrylamide matrix. Chromatographia 28:92-94.

Edman, P., and Begg, G. 1967. A protein sequenator. Eur. J. Biochem. 1:80-91.

Fortin, M. G., Morrison, N. A., and Verma, D. P. S. 1987. Nodulin-26, a peribacteroid membrane nodulin is expressed independently of the development of the peribacteroid compartment. Nucleic Acids Res. 15:813-824.

Fortin, M. G., Zelechowska, M., and Verma, D. P. S. 1985. Specific targeting of membrane nodulins to the bacteroid-enclosing compartment. EMBO J. 4:3041 3046

Jacobs, F. A., Zhang, M., Fortin, M. G. and Verma, D. P. S. 1987. Several nodulins of soybean share structural domains but differ in their subcellular locations. Nucleic Acids Res. 15:1271-1280.

Katinakis, P., and Verma, D. P. S. 1985. Nodulin-24 gene of soybean codes for a peptide of the peribacteroid membrane and was generated by tandem duplication of a sequence resembling an insertion element. Proc. Natl. Acad. Sci. USA 82:4157-4161.

Kouchi, H., and Hata, S. 1993. Isolation and characterization of novel nodulin cDNAs representing genes expressed at early stages of soybean nodule development. Mol. Gen. Genet. 238:106-119.

Kündig, C., Beck, C., Hennecke, H., and Göttfert, M. 1995. A single rRNA gene region in Bradyrhizobium japonicum. J. Bacteriol. 177: 5151-5154.

Laemmli, U. K. 1970. Cleavage of structural proteins during the assembly of the head of bacteriophage t4. Nature 227:680-685.

Legocki, R. P., and Verma, D. P. S. 1980. Identification of "nodulespecific" host proteins (nodulins) involved in the development of $R h i$ zobium-legume symbiosis. Cell 20:153-166.

Lowry, O. H., Rosebrough, N. J., Farr, A. L., and Randall, R. J. 1951. Protein measurements with the folin reagent. J. Biol. Chem. 193:265290.

March, P. E., Ahnn, J., and Inouye, M. 1985. The DNA sequence of the gene $(r n c)$ encoding ribonuclease III of Escherichia coli. Nucleic Acids Res. 13:4677-4685.

Mellor, R. B., Christensen, T. M. I. E., Bassarab, S., and Werner, D. 1985. Phospholipid transfer from ER to the peribacteroid membrane in soybean nodules. Z. Naturforsch. 40c:73-79.

Mellor, R. B., Garbers, C., and Werner, D. 1989. Peribacteroid membrane nodulin gene induction by Bradyrhizobium japonicum mutants. Plant Mol. Biol. 12:307-315.

Mellor, R. B., and Werner, D. 1986. The fractionation of Glycine max root nodule cells: A methodological overview. Endocyt. C. Res. 3: 317-336.

Mellor, R. B., and Werner, D. 1987. Peribacteroid membrane biogenesis in mature legume root nodules. Symbiosis 3:75-100.

Miao, G.-H., Hong, Z., and Verma, D. P. S. 1992. Topology and phosphorylation of soybean $\mathrm{N}-26$, an intrinsic protein of the peribacteroid membrane. J. Cell Biol. 118:481-490.
Morrison, N., and Verma, D. P. S. 1987. A block in the endocytotic release of Rhizobium allows cellular differentiation but affects the expression of some peribacteroid membrane nodulins. Plant Mol. Biol. 7:51-61.

Müller, P., Ahrens, K., Keller, T., and Klaucke, A. 1995a. A TnphoA insertion within the Bradyrhizobium japonicum sipS gene, homologous to prokaryote signal peptidases, results in extensive changes in the expression of PBM-specific nodulins of infected soybean (Glycine max) cells. Mol. Microbiol. 18:831-840.

Müller, P., Klaucke, A., and Wegel, E. 1995b. TnphoA-induced symbiotic mutants of Bradyrhizobium japonicum that impair cell and tissue differentiation in Glycine max nodules. Planta 197:163-175.

Nap, J.-P., and Bisseling, T. 1990. Developmental biology of a plantprokaryote symbiosis: The legume root nodule. Science 250:948-954.

O'Farrell, P. H. 1975. High resolution two-dimensional electrophoresis of proteins. J. Biol. Chem. 250:4007-4021.

Rauhut, R., Jäger, A., Conrad, C., and Klug, G. 1996. Identification and analysis of the $r n c$ gene for RNaseIII in Rhodobacter capsulatus. Nucleic Acids Res. 24:1246-1251.

Roth, L. E., Jeon, K., and Stacey, G. 1988. Homology in endosymbiotic systems: The term "symbiosome". Page 220-225 in: Molecular Genetics of Plant-Microbe Interactions. R. Palacios and D. P. S. Verma, eds. American Phytopathological Society, St. Paul, MN.

Sambrook, J., Fritsch, E. F., and Maniatis, T. A. 1989. Molecular Cloning: A Laboratory Manual. 2nd ed. Cold Spring Harbor Laboratory, Cold Spring Harbor, NY.

Sandal, N. N., and Marcker, K. A. 1988. Soybean nodulin-26 is homologous to the major intrinsic protein of the bovine lens fiber membrane. Nucleic Acids Res. 16:937.

Sanger, F., Nicklen, S., and Coulson, A. R. 1977. DNA sequencing with chain-terminating inhibitors. Proc. Natl. Acad. Sci. USA 74:5463-5467.

Udvardi, M. K., and Day, D. A. 1997. Metabolite transport across symbiotic membranes of legume nodules. Annu. Rev. Plant Physiol. Plant Mol. Biol. 48:493-523.

van Kammen, A. 1984. Suggested nomenclature for plant genes involved in nodulation. Plant Mol. Biol. Rep. 2:43-45.

Verma, D. P. S. 1992. Signals in root nodule organogenesis and endocytosis of Rhizobium. Plant Cell 4:373-382.

Verma, D. P. S., Delauney, A. J., Guids, M., Hirel, B., Schafer, R., and Koh, S. 1988. Control of expresson of nodulin genes. Pages 315-320 in: Molecular Genetics of Plant-Microbe Interactions. R. Palacios and D. P. S. Verma, eds. American Phytopathological Society Press, St. Paul, MN.

Verma, D. P. S., Kazazian, V., Zogbi, V., and Bal, A. K. 1978. Isolation and characterization of the membrane envelope enclosing the bacteroids in soybean root nodules. J. Cell Biol. 78:919-936.

Werner, D., Mörschel, E., Garbers, C., Bassarab, S., and Mellor, R. B. 1988. Particle density and protein composition of the peribacteroid membrane from soybean root nodules is affected by mutation in the microsymbiont Bradyrhizobium japonicum. Planta 174:263-270.

Werner, D., Wilcockson, J., and Zimmermann, E. 1975. Adsorption and selection of rhizobia with ion-exchange papers. Arch. Microbiol. 105:27-32. 